\title{
Midwives' experiences of managing women in labour in the Limpopo Province of South Africa
}

\author{
SM Maputle, D.Cur \\ Senior Lecturer, University of Venda: Department of Advanced Nursing Sience \\ DC Hiss, PHD (Medicine) \\ Professor, University Western Cape: Department of Medical Biosciences
}

\section{Key words}

Accommodative midwifery actions; maximisation of human and material infrastructure; collaboration; interdependence and mutual participation.

\section{Correspondence address}

Dr S. Maputle

Private Bag X 5050

Thohoyandou

0950

Tel: (015) 9628125

Fax:(015) 9628647

E-mail: Sonto.maputle@Univen.ac.za

\begin{abstract}
Curationis 33 (3): 5-14
Introduction: The objective of this study was to explore and describe the experiences of midwives managing women during labour at a tertiary care hospital in the Limpopo Province. An exploratory, descriptive, contextual and inductive design was applied to this qualitative research study. Purposive sampling was used to select midwives who were working in the childbirth unit and had managed women during labour. A sample of 12 midwives participated in this study. Data were collected by means of unstructured individual interviews and analysed through an open coding method by the researchers and the independent co-coder.

Findings: Categories identified were lack of mutual participation and responsibility sharing, dependency and lack of decision-making, lack of information-sharing, empowering autonomy and informed choices opportunities, lack of open communication and listening, non-accommodative midwifery actions, and lack of human and material infrastructure. To ensure the validity of the results, criteria to measure trustworthiness were utilized.

Conclusions: This study has implications for woman-centered care by midwives managing women in labour and provides appropriate guidelines that should be integrated into the Batho-Pele Principles.
\end{abstract}




\section{Introduction}

Midwives form the backbone of maternal, child and women's health in South Africa. Their caring for women during childbirth is a unique life event that is a core function of the midwifery profession. Midwives play a vital role in the implementation of the Batho Pele Principles, Patients' Rights Charter and Millennium Developmental Goals (MDGs). However, limited studies focused on the experiences of midwives managing women during labour. This study explored and described the experiences of midwives who manage women in labour in a tertiary hospital in the Limpopo Province.

\section{Background}

Childbirth, from the perspective of the biomedical model (Pearson, Vaughan and Fitzgerald (1998:36), focuses on the physiological changes that take place during childbirth and the specialized scientific knowledge midwives possess with regard to these changes. The key focus of this model is on the management of labour and the detection of complications or normal childbirth. The situation in hospitals that provide childbirth care is such that prescribed routines are frequently adhered to as laid down in the policies and procedures strategically placed in the ward. Midwives generally regard it as their responsibility to ensure that this code of conduct is not breached. Pearson et al. (1998:34) indicate that the end results of such an approach are standardised routines for maternal care during childbirth. They further point out that women in labour are often expected to comply with a predictable pattern and follow the routine laid down by the regulations. Such standardised routines have some merit, but when followed without skilled assessment may pose a risk of depersonalising the women in labour and discouraging any participation and involvement during midwifery care. This leads to the devaluation of acts related to how women in labour experience their own childbirth, such as listening, comforting or offering choices. Thus, this model is not completely geared to meet the specific needs of women in labour. Pearson et al. (1998:36) view the biomedical model as a reductionist and dualistic approach because it reduces the human body to a set of related parts and further separates the mind from the body. The biomedical model and its dominant effect on healthcare have led to it being used in the interest of midwives, for example, the model concentrates information and decision-making to doctors and midwives, and to a lesser extent to women in labour. The model's emphasis is more on high technology that inherently leads to the loss of personalized and compassionate human care. Women in labour are labelled according to diagnosis rather than being known as patients with needs to be attended to. At the same time, Pearson et al. (1998:37) affirm that the biomedical model is well developed and undoubtedly gives direction to midwifery practice, which is useful. The pressure from society and increased understanding of human rights through the $\mathrm{Pa}$ tients' Charter and Batho-Pele Principles have highlighted the restrictive nature of the biomedical model, the alternative approach being the provision of woman-centred care. The BathoPele Principles seek to introduce a customer-focused approach that aims to put pressure on systems, procedures, attitudes and behaviours within the childbirth units and orient midwifery practice towards the needs and advantages of customers, an approach which puts people first (Department of Public Service and Administration, 1997). The White Paper further indicated that this does not necessarily mean introducing more rules and centralised processes, or micro-managing service delivery activities. Rather, it involves creating a framework for delivery of public services which treats citizens more like customers and enables them to hold public servants to account for the services they render. Healthcare institutions ought to create a people-centered and people-driven service that is characterised by equity, quality, timeousness and a strong code of ethics (Revere \& Black, 2003: 380). The White Paper on Transforming Service Delivery (The Department of Public Service and Administration, 1997) through the eight Batho-Pele Principles (consultation, service standard, courtesy, access, information, openness and transparency, redress and value for money) aims to improve the entire standard of the public service and the effectiveness of service delivery. Services should be based on a customer-orientated framework. The guiding principle adopted within this legal framework is that of Batho-Pele "People First", implying that the consumer of healthcare is placed at the centre of healthcare delivery. It also means that healthcare delivery is transformed in such a way that consumers are satisfied with it (Department of Public Service and Administration, 1997). Sandall (1995:201) supports customeroriented service delivery based on the philosophy that focus should shift from technologisation to personalisation, and thus to the creation of the paradigm of a woman-centered practice based on equal partnership between women in labour and midwives.

\section{Problem Statement}

When mothers are admitted to labour wards, midwives seem to focus mainly on completing certain tasks before handing over the report to the next midwife on duty. Little effort is thus expended on meeting the needs of women in labour as individuals. When managing women in labour during childbirth, midwives follow a set of standards and procedures to monitor and regulate physiological developments. Women in labour, too, are expected to follow the set standards and midwifery protocols. While these policies and procedures might make sense from the standpoint of midwifery care and possibly also reflect the priorities dictated by the biomedical model, they do not always manifest the experiences, needs and priorities of women in labour during childbirth. Also, the experiences of midwives facilitating active participation and decision-making of women during childbirth are not well documented. In view of this paucity, the present study sought to determine the midwives' experiences of managing women who are in labour at a tertiary hospital in the Limpopo Province.

\section{Research Question}

The following research question guided this study: What are the midwives' experiences of managing women during labour at a tertiary hospital in the Limpopo Province?

\section{Purpose Of The Study}

The purpose of the study was to explore and describe the midwives' experiences of managing women during labour in a tertiary hospital in the 
Limpopo Province. The findings of this study were used to develop the womancentered childbirth model (not described here) and guidelines that are integrated within the Batho-Pele Principles It is hoped that these guidelines would assist midwives in the facilitation of mutual participation when managing women during labour.

\section{Definitions Of Terms}

Concepts used in this study are defined as follows:

\section{Experience \\ Experience is an event or circumstance undergone or lived through (Oxford English Dictionary, 2005). In this study, experience refers to all the circum- stances that take place between the midwife and the mother during child- birth.}

\section{In labour}

In this study, in labour refers to the process when a woman gives birth to a child and the midwife managing her. The process includes the first, second and third stages of labour.

\section{Biomedical Model}

Biomedical model refers to the model on which midwives base their practice. In this model, women in labour (patients) are viewed as biological beings and little attention is paid to the wider characteristics of their human nature (Pearson, Vaughan \& Fitzgerald, 1998:27). In this study, the biomedical model refers to the midwife taking full responsibility for controlling the childbirth process without the mother's participation and sharing responsibility.

\section{Meta-theoretical Assumptions}

The meta-theoretical statements of the Batho-Pele Principles (Department of Public Service and Administration, 1997) were used as a frame of reference in this study, with emphasis on putting women in labour first with midwives facilitating mutual participation during this process.

\section{Research Methodology \\ Context}

The study was conducted in a tertiary care hospital in the Limpopo Province which consists of five districts, namely,
Capricorn, Mopani, Vhembe, Sekhukhune and Waterberg. As indicated in the Department of Health Report (2005:52), the total population in the province is estimated at $5514 \mathrm{mil}$ lion of which females constitute 54\%. Of the total female population, $45 \%$ was in the childbearing age group. The health service structure in Limpopo Province consists of 1 tertiary institution, 6 district hospitals (level 2) and 36 community hospitals (level 1 ). Of the 43 hospitals, 40 has functional maternity units for deliveries and an estimated $64 \%$ of the total number of births occur in these hospitals. The tertiary hospital is a referral hospital for levels 1 and 2 hospitals within the province. The current trend is that more women are giving birth in hospitals than at home in the Limpopo province (Department of Health Report, 2005:52).

\section{Research Methodology \\ Procedure of research}

The research design was qualitative, exploratory, descriptive and contextual (McLeod, 2001:54-56), and aimed to provide a description and an exploration of a particular phenomenon or experience within the context of the phenomenon's specific setting and world significance by using a phenomenological approach. Phenomenology is a philosophy and method which stresses the importance of describing and understanding human experience as it is lived, before theorising it (Gu, Zhang \& Ding, 2009).

\section{Population and sampling}

The population consisted of all midwives who were managing women who were in labour in the obstetric unit of a tertiary hospital in the Limpopo Province. Non-probability, convenience and purposive sampling were used in the study. The researchers conveniently sampled the available midwives who were providing midwifery care to women in labour during the active phase of labour (3-10 cm cervical dilatation). Purposive sampling is a type of non-probability sampling in which data are collected from a group of participants chosen for specific key characteristic(Sells, 1997:172). All midwives who had at least two years experience in the obstetric unit and who had agreed to participate were sampled. In this study, the sample was considered adequate only after sufficient data had been collected, saturation had occurred and variation had been accounted for and understood. Saturation means that no new or relevant data seem to emerge for a particular category (Strauss \& Corbin, 1990:188). Twelve (12) midwives had been sampled when saturation was achieved.

\section{Data collection}

Permission to gain entry into childbirth units was obtained following approval from the Ethics Committee of the University of Johannesburg, the Provincial Department of Health, and the hospital concerned. The project was explained to the unit managers and midwives in the obstetrical wards. Written informed consent was obtained from the midwives. A pilot study was conducted with 6 midwives to refine the question (Burns \& Grove, 2005:38). The aim was to see whether the question was clear to the midwives. Midwives understood the question and the interviews were conducted successfully. The question and interview procedure were not changed. These midwives were not included in the main sample. Data were collected by means of unstructured phenomenological in-depth interviews (Burns \& Grove, 2005:130). The unstructured question directed at the midwives was: "Could you please tell me about your experiences of managing women who are in labour?" The interviews were conducted by the researcher in the labour ward's rest room (quiet place), did not exceed 45 minutes and were generally completed within 24 hours of managing and conducting a delivery. The interviews were conducted in English, tape-recorded and midwives assured that sensitive ethical issues such as maintaining confidentiality of data and preserving the anonymity of the participants as well as using research for its intended purposes will be strictly observed (Polit, Beck \& Hungler, 2001:73-89).

\section{Ethical considerations}

The ethical standards as set by Democratic Nursing Organization of South Africa (DENOSA) were adhered to before and during the interview (DENOSA, 1998:1-7). Privacy was ensured during the interview. The participants were assured that their participation was entirely voluntary and 
that they could withdraw from the research project at any stage if they felt like doing so. During the interview, communication skills, for example, probing, were used to obtain the necessary information. Unstructured conversations with midwives were held informally throughout the labour phases. These conversations were spontaneous and emerged from natural social interaction, and contributed to the depth and richness of information that otherwise would have been difficult to capture through more structured interviews. Field notes of events and conversations that occurred when women in labour interacted with their midwives were recorded verbatim.

\section{Data analysis}

Data analysis is a process of bringing order to the data, organising what is collected into concepts, categories and basic descriptive statements (Marshall \& Rossman, 1999:111). Tape-recordings of the interviews were transcribed verbatim in the language in which the interviews were held. The narrative data from unstructured in-depth interviews were analysed qualitatively through the open coding method to develop categories (Tesch, 1990, cited in Cresswell, 2003:192). The independent researcher was also requested to analyse the data according to the open coding method. The two analyses were then compared to ensure trustworthiness. The selection of the analyser was based on experience in qualitative research methodology.

\section{Trustworthiness}

The four criteria of trustworthiness, namely, credibility, dependability, transferability and applicability, as outlined in Lincoln and Guba (1985:301-318), were used to establish the trustworthiness of this study. In this study, credibility was enhanced by the following considerations: the researcher had prolonged exposure to the field of study; the researcher is a midwife, who has knowledge and clinical experience in this area of expertise; the literature consulted enabled the researcher to satisfy the criterion of being knowledgeable about the phenomenon under investigation; the researcher bracketed existing knowledge and preconceived ideas, and especially personal views, about the existing problems in the clini-

Table 1: Categories that emerged from analysis of midwives' experiences of managing women who are in labour

\begin{tabular}{|l|l|}
\hline Category & Description \\
\hline 1. & $\begin{array}{l}\text { Limited mutual participation, responsibility-sharing, decision- } \\
\text { making and dependency }\end{array}$ \\
\hline 2. & $\begin{array}{l}\text { Lack of information-sharing, empowering, autonomy and informed } \\
\text { choices }\end{array}$ \\
\hline 3. & Limited open communication and listening \\
\hline 4. & Non-accommodative midwifery actions \\
\hline 5. & Limited human and material infrastructure \\
\hline
\end{tabular}

cal area; the researcher conducted the unstructured interviews until data saturation occurred, that is, until the collected data were repeated and confirmation of previously collected data had taken place. Furthermore, categories identified by the researcher were compared with those pinpointed by the other coder and no major discrepancies were observed. An in-depth literature review further confirmed these categories. This enhanced confirmability. Transferability was ensured by the researcher via data analysis, interpretation and in-depth discussions in a research report.

\section{Findings And Discussions}

Five categories emerged that described the experiences of midwives who are managing women during labour at a tertiary hospital in the Limpopo Province (Table 1).

\section{Category 1: Limited mutual participation, responsibility- sharing, decision-making and dependency}

Midwives were of the opinion that during labour women did not verbalise that they would like to participate in decision-making. Instead, women followed instructions of midwives. Lundgren and Dahlberg (2002:158) pointed out that it is important for midwives to collaborate with women in labour by inviting them to participate and be responsible for their care during childbirth. Midwives also indicated that some of the women in labour were comfortable with their dependency on the midwives as they indicated that midwives were trained practitioners and knew what is best for them. Since the women in labour depended on midwives, it was evident that they had limited decision-making capability. Bluff and Holloway (2008: 308) affirmed that women often place themselves in the hands of midwives and allow midwives to make decisions for them, even if their own wishes are neglected.

Fabian, Rádestad and Waldenstrõm (2008: 230) further indicated that midwives are challenged to enforce equal opportunities to make information available and to encourage women in labour to take responsibility for their own care. Gibbins and Thomson (2001:310) argued that being included in and making decisions are reported as being crucial in helping women feel in control during labour. According to midwives interviewed, women in labour accepted (without questioning) decisions made by the midwives. This stance placed the midwife in a position of power and authority to make decisions. However, in other instances the mother did not understand why certain decisions were made, but she still complied because of the trust she put in the decision-maker, regardless of what the decision entailed. Ritcher, Greaney, McKeown and Cornell (2001:174) supported this contention by indicating that participative decision-making requires patients be knowledgeable about their healthcare. This means that they should have the ability to process medical information and understand the outcomes of choices they 
make.

Providing midwifery care is potentially stressful when women are not participating in their care during childbirth. Midwives were of the opinion that women in labour do not participate at all in their care and that they displayed limited responsibility-sharing and decision-making during childbirth. These sentiments were supported by one midwife, "The mother may not, however, be willing to participate in her care for various reasons. Some maybe unprepared for childbirth or maybe she had not discussed aspects of participation during pregnancy." Two other midwives indicated that "Women in labour very easily put themselves into the hands of the midwives. I don't know what the cause is or is it because there were no discussions regarding responsibility during pregnancy? But at times there is an attitude in our society that says a pregnant mother is ill and must leave all the responsibility to the midwives because they know best." This was viewed by midwives as a 'dependency syndrome'. Midwives also felt that women were not cooperating during labour.

Midwives were also of the view that their roles were to support the decisions of women during childbirth and that the mother's participation could be strengthened if a therapeutic environment was created. One midwife participant exemplified this by describing how she supported the mother by explaining all procedures to her and promoted her participation by indicating that she had to come up with her preferences for childbirth, and encouraged her to ask questions. The following direct quotations from the midwife support this notion: "Although women in labour did not indicate their behaviour as preferences, they nevertheless participated by adopting a squatting position during childbirth." Another midwife participant said, "You know some women are from a cultural environment where the woman is not used to expressing her wishes as this is not allowed. For example, if the partner is available during childbirth, when asked her wishes, she will look at the partner and expect him to decide."

Midwives could support and give women in labour the opportunity to participate and be responsible during childbirth by being open, listening to women, explaining all procedures, showing respect, and clarifying each other's expectations through the provision of information on childbirth issues and available options. This support will facilitate an environment that is conducive to women becoming more involved and participating willingly in their midwifery care. In woman-centred care, the midwife should take the following into consideration: kindness and respect, listening care, a share in decision-making, and the opportunity for a woman to talk about her care. This approach would facilitate participation during childbirth.

\section{Category 2: Lack of information-sharing, empowering, autonomy and informed choices}

Midwives expressed the opinion that women lack information regarding the childbirth process. Gibbins and Thomson (2001:302) stated that there are many expressions of the need for information, reassurance and confidence-building. They further pointed out that information given during childbirth enables the mother to take decisions and empowers her to make informed choices. In addition, Richter et al. (2001:174) asserted that if women were not given adequate information, they might not be able to collaborate with their physicians or be willing or able to ask questions. Lack of shared information was thus an obvious concern. Sharing of information in advance could build the necessary trust so that goals could be consciously adapted throughout the childbirth process. Limited information, ideas and options are often cited as reasons why women are socialised to accept pain as their lot in life (Mahmoud, 2006: 412). Gibbins and Thomson (2001:302) suggested that information given during childbirth enables the mother to take decisions and empowers her to make informed choices. This idea is supported by the concept that women need to be given information and the opportunity to discuss how that information relates to their particular circumstances. The same concept is reinforced by the assumption that information builds confidence and self-esteem which would enable the mother to take control over her childbirth, ask questions, make informed choices and communicate more effectively with midwives (Fabian,
Rádestad and Waldenstrõm (2008: 233). Midwives have the capability of assisting women in labour to contextualize the information, by creating a relationship of trust through respect. However, Pope, Graham \& Patel (2001:238) cautioned that there are some indications of stereotyped views.

Midwife participants pronounced that women in labour lacked accurate information or knowledge about the understanding and awareness of what should happen during childbirth. During childbirth it was evident that women in labour with accurate and up-to-date information with regard to childbirth issues and the available options were able to make informed choices. The following excerpt from the interviews exemplifies this statement, "When information was shared with regard to childbirth issues and available childbirth options had been outlined, the women in labour would be empowered." One midwife participant who managed women who lacked information said, "Most women who are in labour look confused and don't listen to the instructions carefully. They are anxious and don't co-operate." Another midwife participant said, "Women in labour seemed to be lacking information, some will even refuse to be done vaginal examination during labour. Primigravidae are worse because they close the thighs when the head crowns, but those with little information on what is going to happen, they are better, they do co-operate." It was evident from the transcripts of interviews with midwives that limited information with regard to childbirth issues, available childbirth options and understanding what should happen during childbirth contributed to limited capacity to make informed choices during childbirth by the women.

\section{Category 3: Limited open communication and listening.}

Communication between a midwife and a mother during childbirth should be open and effective. Both parties should understand the language of the other. Midwife participants were of the opinion that women in labour are made to feel free to verbalise their thoughts and wishes during childbirth. They further indicated that they are being open, supportive and that they listen to women and understand their unique 
circumstances and their wishes. From the transcripts of interviews with midwives, language barriers were cited as a factor that interfered with their interaction with women during childbirth. This was the case, especially with women who were transferred from other hospitals and who spoke a language different from that of the midwife. The hospital under study provided midwifery care for all racial groups. Midwives cited that women in labour viewed them as being impatient; that they did not listen; and seldom verified why women in labour had specific preferences. One midwife participant said that, some women who are in labour are difficult and are unable to follow instructions, especially if they don't understand the language." In instances where the midwife spoke a different language, physical presence and touch were found to be beneficial as corroborated by one midwife participant, "The midwife's physical presence helps to establish some contact with the mother if the midwife and mother are not sharing the same language." Communication is key during childbirth. Lack of effective communication between a midwife and a mother may lead to the midwife failing to give a clear explanation about the childbirth process. Language difficulties and lack of information and clarification on the part of the midwife also contribute to misunderstanding

and miscommunication (Ito \& ShartsHopko, 2002:673). In support of this view, Ito and Sharts-Hopko (2002:673) argued that due to lack of English communication with caregivers, women feel that they do not have anything to do. He further indicated that women do not understand the midwife and are therefore unable to ask any questions during childbirth. Limited listening skills lead to ineffective communication. The midwife should display openness, which is a sign of willingness to listen, observe and understand. In some instances, women felt that some procedures were imposed on them. This observation is in agreement with a report by Viisainen (2001) that the way interventions and processes are introduced are usually in an authoritative or non-listening manner, which contributed to women in labour feeling disturbed. On the other hand, midwives also showed concern for the mother as is discussed by McCrea and Crute
(1991) in the study "Midwife/Client Relationship: Midwives' Perspectives", as cited in Doherty (2010:98). The authors observed that women in labour did not listen to midwives, and this led to a feeling of worthlessness. The midwife just went through the process of helping the mother, but no mutual trusting relationship was established.

Takayama and Yamazaki (2003) recognised the need for effective patientphysician communication in childbirth. This is referred to as mutual participation and consultation. Lothian, 2006:297outlined the potential benefits of a birth plan (woman-centred care) with regard to communication as follows: improved channels of communication between the caregivers (midwives) and the consumers (women) and creation of opportunities for discussion of preferences. To the researchers, these benefits would enhance effective communication during childbirth. A birth plan that involves a midwife can give pregnant women information to make choices and help them feel more confident (Lothian, 2006:297; Berg, 2005: 20). Effective communication will then lead to openness and conveyance of safety. According to Lundgren and Berg, (2007:149); Lundgren and Berg (2005:226), a trusting relationship develops that mediates a feeling of tranquility and security. The woman can relax and feel that she is participating in decision-making and thus gain some measure of control of the situation. The emotional aspect of the mother thus becomes supported. Open communication and listening leads to a relationship of trust during midwifery care. One midwife participant indicated that she was firm and honest with women during labour in order to build a relationship of trust, "I think it is important for us midwives to make it clear to women in labour, under our care, for example, by indicating that it is important for me that you have a good childbirth, I'm available for you, I care for you, but you are not the only patient for me, you are my patient right now.". Communication is critical to effective caring during childbirth.

\section{Category 4: Non- accommodative midwifery actions}

Pertaining to the issues of being accommodative, midwife participants deemed that they promoted, supported and respected the values, beliefs and preferences of women as long as they were not harmful to the mother and baby. They were also convinced that some women in labour had unrealistic choices, which could not be accommodated by midwives. One midwife participant said, "I accommodate women' preferences, for example, squatting, but if I find difficulties in managing the childbirth, I explain to the mother the benefits of adopting the dorsal position and guide her in adopting the position”. Fabian et al (2008: 232) suggested that women need to be given information and the opportunity to discuss how that information relates to their particular circumstances before the stresses of labour make it unrealistic to enter into detailed considerations of the pros and cons of childbirth. Some women preferred to have their partners present during labour, which is encouraged, however, midwives had variable preferences and views regarding the presence of a partner during childbirth. One midwife responded, "I allow the presence and support of the partner during delivery because if the companion is present during childbirth he will support by soothing and massaging to the mother." According to Lundgren and Dahlberg (2002:158), the presence of the father interfered with their contact relationship with the mother. This view was echoed by one midwife, "The presence of a companion/partner during childbirth is an obstacle to good a relationship. It is very difficult to establish contact with the mother in the presence of the father who at times displays negative attitude, worry or is aggressive." Another midwife corroborated this feeling, "The presence of the partner interferes with the mother's decision, especially in cultures where husbands are the decision makers. In one incident, when the mother was asked about her wishes, she looked at the husband and asked him to decide. This made me feel that I can't do anything about that." Several authors have spelt out clearly the advantages of the presence of a companion during childbirth (Somers-Smith, 1999:105 cited in Maputle \& Nolte, 2008). However, in most parts of the world, childbirth is still regarded a predominantly female issue, and in the vast majority of traditional cultures it is unbecoming of men 
to be present at birth (Fabian et al, 2008: 235). Midwives raised different opinions with regard to physical comfort during childbirth. According to Bluff \& Holloway (2008: 308), women in labour regard midwives as the practitioners of normal midwifery because "they know best".

\section{Category 5: Limited human and material infrastructure}

Midwives were not able to spend quality time with the women during labour to verify their preferences. A shortage of staff was cited in the interview transcripts. It was pointed out that one midwife might be caring for more than two women at the same time. Pelkonen, Perala and Vehvilainen-Julknnen (1998:22) have found that a busy and routine atmosphere inhibits participation, whereas a friendly, peaceful and secure environment provides opportunities for participation. Tarkka, Paunonen and Laippala (2000:188) cited in Maputle and Nolte, 2008) agreed that in order for midwives to influence positive childbirth experiences, they should display empathy, friendliness, tenderness, calmness, alertness, peacefulness and professional expertise towards women in labour. However, staff shortages tend to jeopardize this positive contribution and often lead to a feeling of tension in clinics and wards.

\section{Recommendations}

The proposal was to create a paradigm of woman-centred care that is based on equal partnership between the midwives and the women who is in labour. The woman-centered care would be integrated in the Batho-Pele Principles. Guidelines to enhance the facilitation of mutual participation (interdependence) were formulated. Chapter 2 of the Constitution of South Africa, through the Bill of Rights, gives citizens the right to take action against the state if they believe their constitutional rights had been infringed upon. It also states that they have the right to access information held by midwives which they need in order to participate in decision-making, exercise informed choices, and enjoy the benefits of autonomy, empowerment and independence (The Constitution, 1996:15). In line with these Constitutional principles, the facilitation of mutual participation is based on the assumptions that the participants have virtually the same power, that they need one another, that the shared activity will be satisfactory to both, and that both become active participants in the development of the nursing care plan (Pera \& Van Tonder, 1996: 58). To realize the Bill of Rights, the Batho-Pele Principles, as a Government initiative to put people first, will be adapted in order to facilitate mutual participation between women in labour and attending midwives during childbirth as follows:

\section{Consultation}

Facilitation of consultation and participative decision-making are aimed at the establishment of the childbirth education programme, which is a client-centred process that builds confidence and self-esteem to enable women in labour to take responsibility and control over their childbirth as active partners. It provides a platform for them to ask questions and seek information so that they can make informed choices and communicate effectively with the attending midwives (Nolte, 1998: 116). The goal of childbirth education programmes is to provide women in labour with useful information on childbirth to acquire a sound knowledge to challenge the rationale of some of the procedures they are expected to undergo. The childbirth education programme is the movement that focuses its attention on teaching women the medical definitions surrounding birth and to prepare women in labour for hospital experiences. When the mother plans to fall pregnant or when she is pregnant, she needs to consult with a midwife who will encourage her to attend the childbirth education programme. The midwife ought to create opportunities for the mother to become a partner. The techniques chosen for a particular mother will be based on needs assessment. During consultation, the midwife is expected to respect the women in labour' past experiences, plans and needs with regard to their childbirth options.

\section{Service standard}

Service standards are commitments to provide a specified level and quality of service to individual customers at any given point in time (Department of Public Service and Administration, 1997). Service standards should be expressed in terms of which are relevant and easily understood by women in labour (women should be able to judge for themselves whether they are receiving what was promised). Service standards should cover the women in labour' main requirements, for example, access (language), courtesy (respect) and provision of information (education). Women in labour must know and understand what quality of service they can expect to receive and what resources they have if the standard is not met. The midwife should create opportunities to inform the mother about the investigations, procedures and results of childbirth and explain (communication) the reasons where the service has fallen short of what was promised.

\section{Access}

The 'White Paper on Transforming Public Service Delivery (1997) states that the service delivery programme should address the needs of all citizens to progressively redress the disadvantages of all barriers to access. During the provision of midwifery care, barriers to access should be taken into consideration in order to facilitate mutual participation as follows: The attitude of the midwife should be approachable; the midwife should respect, encourage and support the mother's cultural and personal preferences and choices; the style of language and choice of words used by the midwife should be carefully considered because words can reflect attitudes of respect or disrespect inclusion or exclusion, judgment or acceptance, i.e., choice of words can either ease or impede communication; and encouragement of decision-making, autonomy, informed choices and personal control (except in situations of clear health risk).

\section{Courtesy}

Midwives have a powerful effect on women who are giving birth. They should be aware that their power to influence impacts both positively and negatively on the mother's childbirth experience. Women in labour tend to remember the specific words and actions of midwives and their satisfaction is linked to the type of care received, feelings of personal control and accomplishment. Midwives are expected to treat all women with cour- 
tesy, respect and dignity during childbirth. When women in labour are treated with courtesy and respect during childbirth, they participate actively in their care. The following actions could be implemented to ensure that courtesy is taken into consideration: the Unit Managers should ensure that the values and behavioural norms of the units are in line with the Principles of Batho-Pele; the performance of midwives who are in contact with women during labour must be regularly monitored and recorded; opportunities should be provided to midwives to suggest ways of improving midwifery care; the training programme that includes day-to-day guidance should be developed in order to ensure that Batho-Pele Principles are implemented in the childbirth unit; and it is proposed that the midwife who renders care to the mother on admission in the hospital be the one who delivers the mother in order to strengthen the relationship of trust.

\section{Information}

Sharing information is a mutual responsibility of the midwife and the mother. The consultation process should be used establish what women in labour need to know and where and when the information can be best provided. This could be achieved through the following actions: the midwives should provide accurate and up-to-date information about the childbirth process, explain it fully by presenting the pros and cons about the care they would provide; when providing information, individual or group teaching methods should be adopted; relevant information should be provided in the womens' own language (access) in order to meet the needs of the mother; the information should be made simple in order to maximize its comprehension and prevent any potential imposition of the attending midwife's view; when presenting information to women in labour, an interval should elapse between the presentation of advantages and disadvantages of the proposed treatment and the patient's decision to ask further questions; the benefits and the risks of all the procedures need to be disclosed and explained, as well as all the options that a mother might consider; midwives need to provide time, support and encouragement to women in labour to explore various options; the written information should be plain and free of jargon -it should be supported by visual aids and other graphical material (e.g., slides, films and videos) to clarify the verbal information and to facilitate understanding, however, cultural relevance should also be considered; handouts on specific topics could be supplied as a method of informing women during childbirth; information about the available services should be communicated to women in labour; when all relevant information has been made available to the mother for the achievement of her goals, she should be guided and not directed by the midwife to share the responsibility for her care during childbirth; information shared between the mother and the midwife is valued by women in labour. Maputle and Nolte (2008: 60) indicated that women viewed attending of classes as a type of insurance because it enables them to feel more secure and informed. The content of childbirth education programmes should be adapted to the needs of the mother and could cover the following: anatomical, physiological, psychological and emotional changes during pregnancy, labour and pueperium, including changes that could affect the partner; prevention and early detection of complications of childbirth; and management and care of minor illnesses encountered during pregnancy, labour and pueperium; pain relief during labour; orientation with regard to the physical surroundings of the labour ward, different techniques used in hospital, basic routines of the hospital and all other aspects of pregnancy, labour and pueperium (adapted from Nolte, 1998:120). However, Fabian et al (2008: 234) is of the opinion that it is very unlikely that the childbirth education programme, as it is currently offered, is making a significant contribution towards putting most women at the centre of their own care and enabling them to participate in decisionmaking about the management of their childbirth.

\section{Openness and transparency}

The White Paper on Transforming the Public Service (1997) indicated that the importance of the public service delivery lies in the need to build confidence and trust between the provider (midwife) and the user (mother). Pera \& Van Tonder (1996:61) indicated that the most satisfactory relationship between the nurse and the patient is character- ized by mutual trust. They further pointed out that trust forms the basis of a successful and effective healthcare relationship.

\section{Conclusion}

From the results of the interviews, it would appear that the tertiary hospital in the Limpopo Province has midwifecentred care rather than woman-centred care during childbirth. In midwifecentred care, the midwife tells the women what to do and how to behave. The approach during childbirth was characterized by limited mutual participation and responsibility-sharing. This comprised of inadequate participation, limited decision-making scope, a proliferation of practices that fostered dependency, and a prevailing authoritative approach within the childbirth unit. The strict routines that were laid down by the regulations seemed to depersonalise the mother, thus resulting in her non-participation. Midwives imposed their authority and responsibility to ensure that the rules were adhered to.

Women who are in labour were seen merely as the ones who should comply with the rules of the unit while having no decision-making power. There was also an over-reliance on technology. Limited information-sharing and empowering were displayed in this approach. Information regarding childbirth issues and awareness of available options was not shared with the women in labour. This resulted in a feeling of powerlessness and a lack of autonomy in childbirth care. Hindered or ineffective communication, such as, inadequate listening skills of attending midwives and the existence of a language barrier between women and midwives often resulted in limited participation by the women in labour. The midwifecentred care approach was confined to the physiological processes of childbirth while the psychosocial aspects of the mother were ignored. Non-accommodative midwifery actions that had been poorly defined in terms of perceptions of conflicting expectations and unrealistic choices of the mother were manifested. In midwife-centred care, the management of childbirth focused on the detection of complications. This did not always respect the experience and expectations of childbirth and its outcome. 


\section{Limitations of the study}

There were no limitations of the study except possible bias on the part of the persons who did the analysis and interpretation of the data.

\section{References}

BERG, M 2005: A Midwifery Model of Care for Childbearing Woman at High Risk: Genuine Caring in Caring for the Genuine. Journal of Perinatal Education, 14 (1): $9-21$.

BLUFF, R \& HOLLOWAY, I 2008: The efficacy of midwifery role models. Midwifery, 24 (3); 301-309.

BURNS, N \& GROVE, SK 2005: The practice of nursing research: conduct, critique and utilization. London: WB Saunders Company: W.B. Saunders

CRESWELL, JW 2003: Research Design: Qualitative and Quantitative approaches. Thousand Oaks, London New Delhi, Sage Publishers.

DEMOCRATIC NURSES' ORGANISATION OF SOUTH AFRICA (DENOSA) 1998: Ethical Standards for Nurse Researcher. Pretoria: DENOSA.

DEPARTMENT OF PUBLIC SERVICESAND ADMINISTRATION 1997: People First: White Paper on Transforming Public Service Delivery. Pretoria: Staatskoerant.

DOHERTY, ME 2010: Voices of Midwives: A tapestry of Challenges and Blessings. American Journal of Maternal Child nursing, 35 (2): 96 - 101.

FABIAN, IJ; RÃDESTAD, U \& WALDENSTRÕM U 2008: Characteristics of Swedish women who do not attend childbirth and parenthood education classes during pregnancy. Midwifery, 20 (3) 226-235.

GIBBINS, J \& THOMSON, AM 2001: Women's expectations and experiences of childbirth. Midwifery, 17, 302-313.

\section{GU, C; ZHANG, Z \& DING, Y 2009:}

Chinese midwives' experience of providing continuity of care to laboring women. Midwifery, doi:10.1016/ j.midw.2009.06.007.

ITO, M \& SHARTS-HOPKO, NC
2002: Japanese Women's experience of childbirth in the United States. Health care for women International, 23, 666-677.

LINCOLN, M \& GUBA, EG 1985: Criteria for assessing trustworthiness of naturalistic inquiry. Thousand Oaks: Sage Publications.

LOTHIAN, J 2006: Birth plans, the good, the bad, and the future. Journal of Obstetric, Gynecologic, and Neonatal Nursing, 35, 295-303.

LUNDGREN, I \& BERG, M 2007: Central concepts in the midwife-woman relationship. Scandinavian Journal of Caring Sciences, 21 (2): 145-288.

LUNDGREN, I \& DAHLBERG, K 2002: Midwives' experience of the encounter with women and their pain during childbirth. Midwifery, 18, 155-164.

LUNDGREN, I \& DAHLBERG, K 2005: Central concepts in the midwifewoman relationship. Scandinavian Journal of Caring Sciences, 21, 220-228.

MAHMOUD, FF 2006: Human rights aspect of safe motherhood. Clinical Obstetrics and Gynecology, 20 (3): 409419.

MAPUTLE,MS \& NOLTE,AWG2008: Mothers' experience of labour in a tertiary care hospital. Health SA Gesondheid Vol. 13 (1), 55-62.

MARSHALL, C \& ROSSMAN, GB 1999: Designing qualitative research. Thousand Oaks, California: Sage

MCLEOD, J 2001: Qualitative research in counseling and psychotherapy. London: Sage.

NOLTE, AGW (ED) 1998: A textbook for midwives. Pretoria: J.L. Van Schaik.

OXFORD ENGLISH DICTIONARY 2005: Oxford, University Press.

PEARSON, A; VAUGHAN, B \& FITZGERALD, M 1998: Nursing Models for Practice. Melbourne, Johannesburg: Butterworth-Heinemann.

PELKONEN, M; PERALA, ML \& VEHVILAINEN-JULKNNEN,K.1998: Participation of expectant mothers in decision-making in maternity care: results of a population-based survey. Journal of Advanced Nursing, 28 (1), 21-29.

PERA, SA \& VANTONDER, S (EDS) 1996: Ethics in Nursing Practice. Cape Town: Juta \& Co. Ltd.

POLIT,DF; BECK, CT \& HUNGLER, BP 2001: Nursing research: Principles and methods; $5^{\text {th }}$ edition. Philadelphia: Lippincott.

POPE, R; GRAHAM, L \& PATEL, S 2001: Woman-centred care. International Journal of Nursing Studies, 2001:38(2), 227-238.

REVERE, L \& BLACK, K 2003: Integrating six sigma with total quality management: A case example for measuring medication errors. Journal of Healthcare Management, 48 (6): 377391.

RITCHER, DL; GREANEY, ML; MCKEOWN, RE; CORNELL, CE; LITTLETON, MA\& PULLEY,L 2001: Developing a Video Intervention to Model Effective Patient-Physician Communication and Health-related Decision-making Skills for a Multi-Ethnic Audience. JAMWA, 56 (4), 174-176.

SANDAL, J 1995: Choice, continuity and control: Changing Midwifery towards a Social Perspective. Midwifery, 11, 201-209.

SELLS, SP 1997: Teaching Ethnographic Methods in Social Work Course. Journal of Social Work Education, 33, 167.

SOUTHAFRICA: HEALTHCARE IN LIMPOPO PROVINCE 2005: Implications for planning. Durban: Health Systems Trust.

STRAUSS, A \& CORBIN, J 1990: Basics of Qualitative Research: Grounded Theory Procedures and Techniques. Newbury Park: Sage Publications.

TAKAYAMA, T \& YAMAZAKI, Y 2003: How breast cancer outpatients perceive mutual participation in patient-physician interactions. Patient Education and Counseling. 2003: 1-11. 
TARKKA, MT; PAINONEN, M \&

LAIPPALA, P 2000: Importance of Midwife in the First time Mother's experience of childbirth. Scandinavian Journal Caring Science, 14: 184-190.

VIISAINEN, K 2001: Negotiating control and meaning: home birth as a selfconstructed choice in Finland. ScienceDirect http:// www.sciencedirect.com/science? $\mathrm{ob}=$ Article URL 256. Accessed on the 25.06.2009. 